University of Montana

ScholarWorks at University of Montana

Numerical Terradynamic Simulation Group

Publications

Numerical Terradynamic Simulation Group

$5-2012$

\title{
Increasing subsurface water storage in discontinuous permafrost areas of the Lena River basin, Eurasia, detected from GRACE
}

I. Velicogna

J. Tong

T. Zhang

John S. Kimball

University of Montana - Missoula

Follow this and additional works at: https://scholarworks.umt.edu/ntsg_pubs

Let us know how access to this document benefits you.

\section{Recommended Citation}

Velicogna, I., J. Tong, T. Zhang, and J. S. Kimball (2012), Increasing subsurface water storage in discontinuous permafrost areas of the Lena River basin, Eurasia, detected from GRACE, Geophys. Res. Lett., 39, L09403, doi:10.1029/2012GL051623

This Article is brought to you for free and open access by the Numerical Terradynamic Simulation Group at ScholarWorks at University of Montana. It has been accepted for inclusion in Numerical Terradynamic Simulation Group Publications by an authorized administrator of ScholarWorks at University of Montana. For more information, please contact scholarworks@mso.umt.edu. 


\title{
1 Increasing subsurface water storage in discontinuous permafrost 2 areas of the Lena River basin, Eurasia, detected from GRACE
}

\author{
3 I. Velicogna, ${ }^{1,2}$ J. Tong, ${ }^{1}$ T. Zhang, ${ }^{3,4}$ and J. S. Kimball ${ }^{5}$ \\ 4 Received 9 March 2012; accepted 26 March 2012; published XX Month 2012.
}

5 [1] We use monthly measurements of time-variable gravity 6 from the GRACE (Gravity Recovery and Climate Experi-

7 ment) satellite mission to quantify changes in terrestrial 8 water storage (TWS) in the Lena river basin, Eurasia, during 9 the period April 2002 to September 2010. We estimate a 10 TWS increase of $32 \pm 10 \mathrm{~km}^{3} / \mathrm{yr}$ for the entire basin, equiv11 alent to an increase in water thickness of $1.3 \pm 0.4 \mathrm{~cm} / \mathrm{yr}$ 12 over a basin of 2.4 million $\mathrm{km}^{2}$. We compare TWS estimates 13 from GRACE with time series of precipitation (P) minus 14 evapotranspiration (ET) from ERA-Interim reanalysis minus 15 observational river discharge $(\mathrm{R})$. We find an excellent 16 agreement in annual and inter-annual variability between the 17 two time series. Furthermore, we find that a bias of $-20 \pm 10 \%$ 18 in P-ET is sufficient to effectively close the water budget with 19 GRACE. When we account for this bias, the time series of 20 cumulative TWS from GRACE and climatological data agree 21 to within $\pm 3.8 \mathrm{~cm}$ of water thickness, or $\pm 9 \%$ of the mean 22 annual $P$. The TWS increase is not uniform across the river 23 basin and exhibits a peak, over an area of $502,400 \mathrm{~km}^{2}$, 24 centered at $118.5^{\circ} \mathrm{E}, 62.5^{\circ} \mathrm{N}$, and underlain by discontinuous 25 permafrost. In this region, we attribute the observed TWS 26 increase of $68 \pm 19 \mathrm{~km}^{3}$ to an increase in subsurface water 27 storage. This large subsurface water signal will have a sig28 nificant impact on the terrestrial hydrology of the region, 29 including increased baseflow and alteration of seasonal run30 off. Citation: Velicogna, I., J. Tong, T. Zhang, and J. S. Kimball 31 (2012), Increasing subsurface water storage in discontinuous perma32 frost areas of the Lena River basin, Eurasia, detected from GRACE, 33 Geophys. Res. Lett., 39, LXXXXX, doi:10.1029/2012GL051623.

\section{1. Introduction}

35 [2] Recent studies show substantial changes in the Arctic 36 terrestrial hydrological system [e.g., Rawlins et al., 2010]. 37 Most of these analyses have focused on precipitation $(\mathrm{P})$, 38 evapotranspiration (ET), and river discharge (R) [Serreze 39 et al., 2002, 2006; White et al., 2007; Rawlins et al., 2010].

\footnotetext{
${ }^{1}$ Department of Earth System Science, University of California, Irvine, California, USA

${ }^{2}$ Jet Propulsion Laboratory, California Institute of Technology, Pasadena, California, USA USA.

${ }^{3}$ NSIDC, CIRES, University of Colorado at Boulder, Boulder, Colorado,

${ }^{4}$ MOE Key Laboratory of West China's Environmental System, Lanzhou University, Lanzhou, China.

${ }^{5}$ Flathead Lake Biological Station, University of Montana, Polson, Montana, USA.
}

Corresponding Author: I. Velicogna, Department of Earth System Science, University of California, 3226 Croul Hall, Irvine, CA 92697-3100, USA. (isabella (a)uci.edu)

Copyright 2012 by the American Geophysical Union 0094-8276/12/2012GL051623
Comparatively less attention has been paid to terrestrial water 40 storage (TWS), which is calculated as a residual of these 41 other water balance components. Changes in the Arctic ter- 42 restrial water cycle, especially the storage component, alter 43 soil moisture and thermal regimes, and thus affect plant 44 communities and land-atmosphere water, energy and trace 45 gas exchanges, with potentially large climate feedbacks. 46 Recent warming over northern land areas has altered regional 47 atmosphere circulation and precipitation patterns, deepening 48 the soil active layer and destabilizing the upper permafrost 49 layers [Zhang et al., 2005].

[3] In this study, we directly address the issue of changes 51 in TWS using time-variable gravity data from the GRACE 52 mission. We focus our analysis on the Lena river basin, 53 Eurasia, a region of about $2,400,000 \mathrm{~km}^{2}$ in size. Most of the 54 Lena river basin is underlained by permafrost: about $79 \% \quad 55$ with continuous permafrost, and the remainder with dis- 56 continuous permafrost [Zhang et al., 2005]. Previous studies 57 using GRACE data have revealed an increase in TWS in the 58 Lena basin [Muskett and Romanovsky, 2009; Troy et al., 59 2011] and found a qualitative agreement between TWS 60 estimated using GRACE and ancillary climatological data 61 [Landerer et al., 2010]. Here, we present a more detailed, 62 quantitative analysis and attribution of these changes in the 63 water budget. We examine if the GRACE data can be used 64 to estimate the bias in net precipitation (P-ET) from reanal- 65 ysis output, and quantify the agreement between TWS from 66 GRACE versus TWS from climatological data and obser- 67 vational river discharge. We discuss the spatial patterns of 68 TWS revealed by GRACE, determine the partitioning of the 69 sources of the change in TWS and their impact on the 70 hydrological cycle.

\section{Data and Methodology}

[4] We use 99 monthly GRACE gravity field solutions, in 73 the form of spherical harmonic coefficients, generated at the 74 Center for Space Research at the University of Texas between 75 April 2002 and September 2010 [Tapley et al., 2004]. Each 76 solution consists of spherical harmonic (Stokes) coefficients 77 up to degree 60. GRACE does not recover degree-1 coeffi- 78 cients. We calculate these coefficients by combining GRACE 79 data with ocean model output as in Swenson et al. [2008]. We 80 replace the GRACE $C_{20}$ coefficients with values derived from 81 satellite laser ranging [Cheng and Tapley, 2004]. The GRACE 82 data directly reveal anomalies in TWS, because this is the 83 largest source of mass change within our area of interest; other 84 mass changes such as glacial isostatic adjustment (GIA) are of 85 much lower magnitude. TWS anomalies are calculated relative 86 to the period August 2002-August 2009, which is the longest 87 period common to all observations used in our analysis. To 88 reduce the influence of seasonal variability on the long-term 89 trend, we apply a 13-month moving average to the monthly 90 


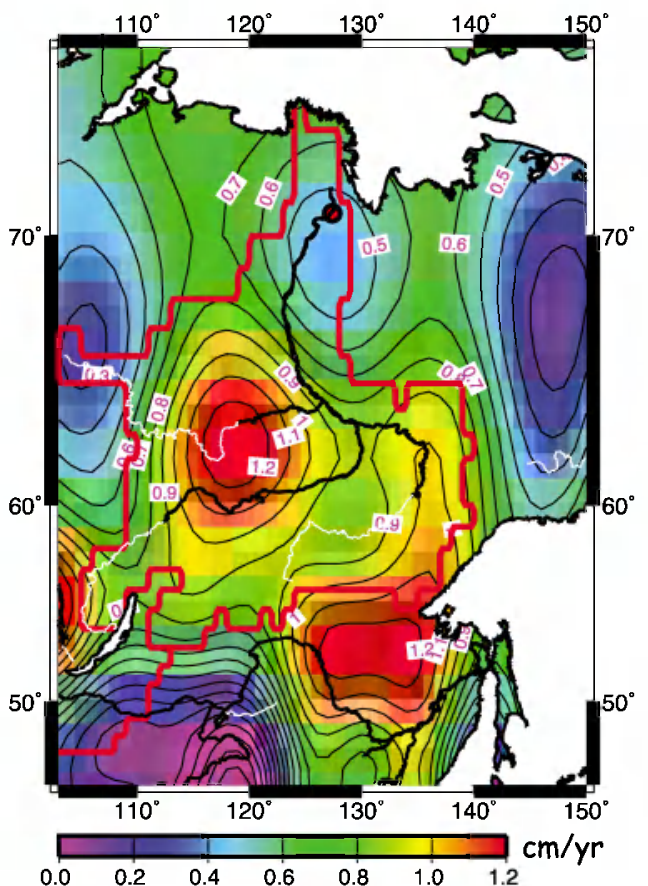

Figure 1. Rate of change of Terrestrial Water Storage (TWS), in $\mathrm{cm} / \mathrm{yr}$ of water thickness, determined from GRACE data for April 2002-September 2010. River basin boundaries (red line) and river gauge location (red circle) are shown.

91 Stokes coefficients. This yields a smoothed time series where 92 seasonal variations are reduced. We simultaneously fit an 93 annual, a semiannual, and a linear trend to the smoothed 94 Stokes coefficient time series. To reduce the random error 95 component, which increases as a function of decreasing 96 wavelength, we smooth the data using a Gaussian filter with a $97350 \mathrm{~km}$ radius [Wahr et al., 1998]. To isolate the TWS signal, 98 the GRACE data are corrected for the GIA signal following 99 Paulson et al. [2007]. The correction is less than $2 \%$ of the 100 GRACE signal. We then generate an evenly spaced latitude101 longitude grid. The trend in TWS is shown in Figure 1.

102 [5] GRACE Stokes coefficients can be used to estimate 103 water storage variations averaged over a specific region by 104 constructing an averaging function optimized for the region. 105 To calculate monthly TWS averaged over the Lena basin we 106 construct an averaging kernel convolving a $250 \mathrm{~km}$ half107 width Gaussian function with the basin mask (1 inside the 108 basin and 0 outside) and we apply the kernel to the GRACE 109 data. Because the signal we are interested in recovering is 110 not uniform across the region boundaries and across the 111 basin, the choice of the kernel is critical. We construct var112 ious kernels corresponding to Gaussian functions of differ113 ent halfwidth (from $300 \mathrm{~km}$ to $0 \mathrm{~km}$ ). We discard the kernels 114 that produce an uneven sampling of the basin. For each of 115 the remaining kernels, we calculate a scaling factor and a 116 mass estimate error. The scaling factor is calculated assum117 ing a synthetic mass change equal to the GLDAS-NOAH 118 model TWS trend [Rodell et al., 2004] over the study region, 119 processing it in the same manner as the GRACE data, i.e., 120 converting it to the spectral domain, truncating it to degree 12160 and spatially averaging it using the averaging kernel, and 122 comparing the retrieved signal with the original synthetic. 123 Uncertainties in the Stokes coefficients are determined by assuming that the scatter of the monthly values about their 124 seasonal cycle is due entirely to errors [Wahr et al., 2006]. 125 This represents the upper bound on the random component 126 of the error. The 1- $\sigma$ error estimates in the spatially averaged 127 GRACE time series are then calculated from the uncertainty 128 in the individual Stokes coefficients. We choose the kernel 129 that produces the smallest mass error and the most uniform 130 sampling of the basin. The corresponding scaling factor is 1.3, 131 and the mass errors for the averaged monthly TWS and for the 132 trend are $\pm 22 \mathrm{~km}^{3}$ and $\pm 6 \mathrm{~km}^{3} / \mathrm{yr}$, respectively. Figure 2133 shows the rescaled monthly averaged TWS anomalies.

[6] Errors in the GRACE TWS signal are a combination of 135 errors in the GRACE gravity fields, leakage from other 136 geophysical sources and procedure errors. The uncertainty 137 caused by leakage from outside the region is estimated by 138 applying our solution process to the GRACE signal, after 139 first removing our best-fitting monthly estimates for the 140 Lena, and then fitting a trend to the residual [Tiwari et al., 141 2009]. We calculate the total uncertainty in the GRACE 142 TWS as the root-sum-square of errors in the GRACE gravity 143 field solutions, GIA correction, leakage, averaging process 144 and fit errors.

[7] The increase in TWS (Figure 1) exhibits a strong 146 anomaly near the center of the basin at $118.5^{\circ} \mathrm{E}$ and $62.5^{\circ} \mathrm{N}, 147$ in a region $502,400 \mathrm{~km}^{2}$ in size, and characterized by dis- 148 continuous permafrost; hereafter referred to as the Lena 149 subregion. To calculate the monthly TWS averaged over this 150 subregion, we generate an averaging kernel following the 151 procedure described above. We define a mask for the sub- 152 region (1 inside a region corresponding to a $400 \mathrm{~km}$ disc 153 centered at $118.5^{\circ} \mathrm{E}$ and $62.5^{\circ} \mathrm{N}$ and 0 outside), and we 154 select an exact (radius $=0-\mathrm{km}$ ) averaging function, i.e., no 155 Gaussian averaging, as it samples the subregion uniformly 156 and we find that GRACE measurements errors are not sig- 157 nificantly larger in the case of $R=0$ compared to $R>0$. Note 158 that truncation to degree 60 produces some smoothing of the 159 signal, even in the case of $\mathrm{R}=0$. For this kernel we estimate 160 a scaling factor of 1.15. In this case, because the TWS is 161

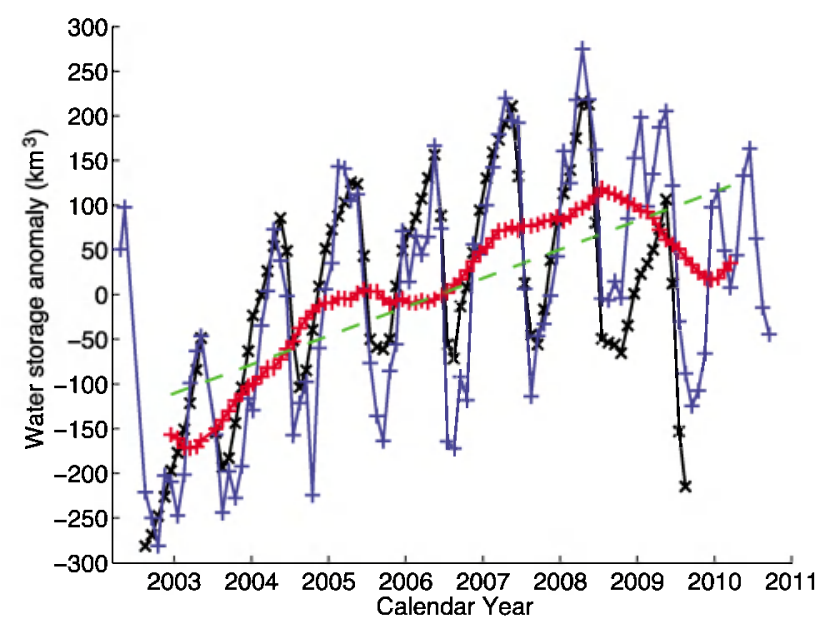

Figure 2. Time series of terrestrial water storage (TWS) changes for the Lena basin from GRACE monthly mass solutions (blue crosses) and from accumulated P-ET-R from ERA-interim reanalysis and river discharge data (black crosses). GRACE data filtered for seasonal dependence are denoted as red crosses; the best fit linear trend for the GRACE time series is shown as a green line. 


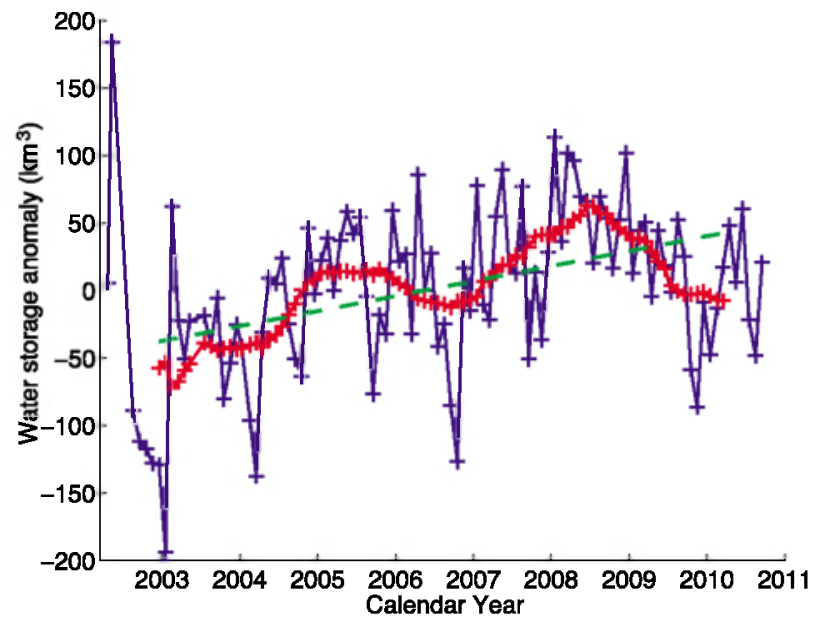

Figure 3. Time series of GRACE terrestrial water storage (TWS) changes for the Lena subregion. Unfiltered data are denoted as blue crosses. Data filtered for seasonal dependence are denoted red crosses. The best-fitting trend is shown as a green line.

162 uniform across the region, the scaling factor is calculated by 163 applying the averaging function to a uniform $1-\mathrm{cm}$ water 164 mass change spread evenly over the subregion. We evaluate 165 the uncertainty in the scaling factor associated to the spatial 166 distribution of the mass change within the subregion by 167 calculating the sensitivity to different mass distributions. We 168 find an uncertainty of $1 \%$ which we include in our final error 169 budget. Figure 3 shows the resulting monthly spatially 170 averaged TWS anomalies for the Lena subregion.

171 [8] Independently, we estimate monthly TWS changes for 172 the Lena basin from climatological data, i.e., P-ET-R. We use 173 ERA-Interim forecast monthly $\mathrm{P}$ and ET [e.g., Simmons 174 et al., 2007] and monthly $\mathrm{R}$ data for the Lena river gauge at 175 Kusur (station Code: 3821, Lat/Lon: $70.68^{\circ} \mathrm{N} / 127.39^{\circ} \mathrm{E}$ ) 176 located at the Lena river delta [Lammers et al., 2001]. Dis177 charge data are available only through August 2009. Esti178 mated errors in river discharge range from 3 to $8 \%$ 179 [Shiklomanov et al., 2006]; here we assume a conservative 180 error of $10 \%$. For P-ET, we use an error estimate of $25 \%$ 181 based on previous studies [Serreze et al., 2006; Rawlins et al., 182 2010]. The climatological data are processed in the same 183 manner as the GRACE data, i.e., converted to the spectral 184 domain, truncated to degree 60 , and spatially averaged.

\section{3. Results}

186 [9] We calculate a TWS gain of $32 \pm 10 \mathrm{~km}^{3} / \mathrm{yr}$ for the Lena 187 basin from December 2002 to March 2010, which is equiva188 lent to an average water thickness of $1.3 \pm 0.4 \mathrm{~cm} / \mathrm{yr}$. The 189 mean annual P-ET from ERA-Interim is $19.2 \mathrm{~cm}$ for the basin. 190 In the Lena subregion, the GRACE data reveal a TWS gain of $19111 \pm 6 \mathrm{~km}^{3} / \mathrm{yr}(2.2 \pm 1.2 \mathrm{~cm} / \mathrm{yr}$ equivalent water thickness $)$ 192 and a cumulative storage increase of $80 \pm 16 \mathrm{~km}^{3}(16 \pm 3 \mathrm{~cm}$ 193 equivalent water thickness) over the entire study period.

194 [10] We estimate the component of the TWS change in 195 Lena subregion. The TWS change estimated from GRACE 196 includes mass contributions from groundwater, soil water, 197 surface water (lakes), snow, ice, and vegetation biomass. 198 The vegetation biomass signal has been shown to be well 199 below the detection limits of GRACE [Rodell et al., 2005], so biomass is not a factor here, especially in the case of the 200 Lena basin which is dominated by tundra. To estimate the 201 TWS contribution from snow cover changes, we use $25 \mathrm{~km} 202$ EASE-Grid monthly snow water equivalent (SWE) data 203 from the Advanced Microwave Scanning Radiometer on 204 EOS Aqua (AMSR-E) (http://nsidc.org/data/amsre/) [Derksen 205 et al., 2003]. The retrieval accuracy for SWE from satellite 206 passive microwave sensors, including AMSR-E, is generally 207 higher for flatter regions with less vegetation cover. This is the 208 case of the Lena subregion which is relatively flat and largely 209 covered by tundra. We estimate that changes in snow mass 210 represent only $10 \%$ of the total TWS increase in the Lena 211 during the entire 7 -year period (i.e., $1 \mathrm{~km}^{3} / \mathrm{yr}$, or $7 \mathrm{~km}^{3}$ for the 212 entire period). This result is similar to station observation 213 based cold season precipitation trends for the region [Rawlins 214 et al., 2009]. If we remove the SWE contribution from the 215 GRACE TWS estimates, we obtain an adjusted storage trend 216 of $10 \pm 7 \mathrm{~km}^{3} / \mathrm{yr}$ for the Lena subregion. We assume a con- 217 servative estimate of SWE error of $1 \mathrm{~km}^{3} / \mathrm{yr}$, or $100 \%$. $\quad 218$

[11] We estimate the TWS signal leakage from outside the 219 subregion to be $5 \mathrm{~km}^{3}$ for the entire analyzed period. After 220 correction for leakage, we obtain an adjusted TWS trend of 221 $9 \pm 7 \mathrm{~km}^{3} / \mathrm{yr}(1.8 \pm 1 \mathrm{~cm} / \mathrm{yr})$ and total storage increase of 222 $68 \pm 19 \mathrm{~km}^{3}(13.6 \pm 3.8 \mathrm{~cm})$ for the 7 -year period for the 223 subregion.

[12] We estimate an upper bound of lake water storage 225 contribution using increasing surface inundation trends for 226 the Lena subregion detected from the satellite microwave 227 (AMSR-E) remote sensing record. We calculate the total 228 increase in land fractional cover of open water during sum- 229 mer (JJA) non-frozen conditions using a global daily land 230 parameter record from AMSR-E from 2002 to 2008 [Jones 231 and Kimball, 2010]. In the Lena subregion, the AMSR-E 232 record shows an average inundation increase of $0.02 \%$ per 233 year that corresponds to a total increase in inundated area of 234 $600 \mathrm{~km}^{2}$ for the 7-year period. Even assuming a $5 \mathrm{~m}$ depth 235 increase in water storage over the $600 \mathrm{~km}^{2}$ region (this 236 represents an upper bound for the increase in lake storage 237 given the flat terrain of the Lena basin), the entire inundated 238 area should only account for $3 \mathrm{~km}^{3}$ of the observed $68 \mathrm{~km}^{3}, 239$ or 5\% of the observed signal. We conclude that the GRACE- 240 derived positive TWS trend is largely due to an increase in 241 soil and groundwater storage, which we denote hereafter as 242 subsurface water storage.

[13] Turning to the TWS from climatological data, we 244 may assume that discharge (R) observations from gauges are 245 unbiased [Shiklomanov et al., 2006]. On the other hand, 246 there is an unknown bias in P-ET from reanalysis that is 247 difficult to estimate [Serreze et al, 2006]. A bias in P-ET 248 represents an offset in the P-ET time series but an offset and 249 a trend in the cumulative time series. If we do not remove the 250 bias, it is not possible to compare the trend of the accumu- 251 lated TWS from P-ET-R and GRACE. Hence we compare 252 the de-trended time series of monthly TWS from GRACE 253 and accumulated P-ET-R, and we find that they agree to 254 within $\pm 19 \%$ and $\pm 14 \%$ with and without accounting for 255 the autocorrelation, respectively. Both time series show 256 strong seasonal variability which coincides in phase but the 257 P-ET-R signal has a smaller amplitude.

[14] We have high confidence that the GRACE-derived 259 TWS is not affected by residual bias because we remove all 260 biases in our analysis. If we assume conservation of water 261 mass, we may estimate the average annual bias in P-ET that 262 
263 best matches TWS from GRACE plus R. We find an average 264 annual bias of $-4.5 \pm 2.4 \mathrm{~cm}$ of water for the entire basin, or $265-20 \pm 10 \%$ of the average annual P-ET. This value is within 266 the error bounds in P-ET from the reanalysis data and agrees 267 in magnitude and sign with an independent estimate from 268 Serreze et al. [2006].

269 [15] Figure 2 shows the time series of accumulated P-ET-R 270 corrected for the bias. The data agree to within $\pm 1.9 \mathrm{~cm}$ of 271 equivalent water thickness with GRACE when we account 272 for auto-correlation. When we account for all sources of 273 error, we effectively close the water budget to within $\pm 9 \%$ 274 of the mean annual precipitation $(\sim 47 \mathrm{~cm})$.

\section{4. Discussion}

276 [16] GRACE measurements of time-variable gravity 277 reveal a TWS increase of $32 \pm 10 \mathrm{~km}^{3} / \mathrm{yr}$ in the Lena basin 278 during the period April 2002-September 2010. Previous 279 studies using GRACE data showed evidence of a TWS 280 increase for the Lena basin but did not quantify the magni281 tude of TWS increase [Landerer et al., 2010; Troy et al., 282 2011; Sahoo et al., 2011] and did not account for bias 283 effects or leakage from surrounding regions on the GRACE 284 water storage signal [Muskett and Romanovsky, 2009]. Here, 285 we quantify the TWS increase for the Lena and find a strong 286 agreement between independent storage trends derived from 287 GRACE and climatological data.

288 [17] Several studies have identified biases in P-ET from 289 re-analysis data [Serreze et al., 2006; Simmons et al., 2007]. 290 Due to sparse ground observations and regional water bud291 get uncertainties, it is difficult to estimate the bias. Here, we 292 estimate this bias using GRACE data, assuming that the bias 293 is constant over the period of record and applying water 294 mass conservation. In reality, the bias may be time depen295 dent [Serreze et al., 2006; Landerer et al., 2010], but this is 296 beyond the scope of the paper. Here, our goal is to close the 297 regional water budget over 7 years.

298 [18] Previous analysis by Sahoo et al. [2011] reports water 299 budget closure for the Lena basin to within $\pm 25 \%$ of the 300 mean annual precipitation, with the uncertainty attributed 301 mainly to $P$ and storage terms from GRACE. The authors 302 used monthly GRACE TWS gridded data averaged with a $303750 \mathrm{~km}$ gaussian smoothing, but did not correct for the bias 304 in the GRACE data caused by smoothing and leakage. Here, 305 we correct for GRACE errors and for the bias in P-ET to 306 close the regional water budget to within $\pm 9 \%$ of the mean 307 annual precipitation, i.e., an error reduction by a factor 3 .

308 [19] The observed TWS increase for the Lena subregion is 309 twice as large as in the rest of the basin and is associated 310 with an increase in subsurface water storage of $9 \pm 7 \mathrm{~km}^{3} / \mathrm{yr}$ $311(1.8 \pm 1 \mathrm{~cm} / \mathrm{yr})$ and cumulative storage increase of $13.6 \pm$ $3123.8 \mathrm{~cm}$ from December 2002 to March 2010. We have no 313 measurement of the groundwater table within the active 314 layer in that region. We estimate that a potential $10 \mathrm{~cm}$ rise 315 of the groundwater table toward the surface corresponds to 316 an average groundwater storage increase of $2.4 \mathrm{~cm}$ in the 317 Lena subregion, assuming a specific yield of 0.24 typical of 318 tundra soils [Johnson, 1967]. A $56 \mathrm{~cm}$ rise in the ground319 water table from 2002 through 2010 would be required to 320 account for the subsurface water storage increase measured 321 by GRACE. An increase in the active layer thickness (ALT) 322 may also increase groundwater storage in this subregion. 323 Zhang et al. [2005] analyzed regional soil temperature measurements and estimated a mean ALT of $1.9 \mathrm{~m}$, and 324 ranging from 1.2 to $2.9 \mathrm{~m}$ for the Lena basin; they also 325 identified a $31 \pm 9 \mathrm{~cm}$ increase in mean ALT from 1956- 326 1990. Since the 1990s, air temperatures over Siberia have 327 increased significantly so the ALT should have increased at 328 an even greater rate than for previous decades. The relatively 329 conservative 1956-1990 trend would produce an ALT 330 increase of $8 \mathrm{~cm}$ for the 7-year study period. An $8 \mathrm{~cm} 331$ decrease in ground water level over the same period repre- 332 sents $1.9 \mathrm{~cm}$ of potential additional soil water storage aver- 333 aged over the region, but would account for only $14 \%$ of the 334 TWS change detected by GRACE. However, much of the 335 upper permafrost layer is generally ice rich [Brown et al., 336 1997]. When the active layer thickens, meltwater from 337 ground ice near the permafrost table keeps the newly thawed 338 layer saturated and leaves little or no room for lowering the 339 groundwater table within the active layer, resulting in little 340 or no change in ground water storage. Therefore, we con- 341 clude that changes in ALT have relatively little impact on 342 the observed TWS change.

343

[20] Over the Lena subregion, the fractional area of dis- 344 continuous permafrost ranges from 30 to $40 \%$, with non- 345 permafrost areas covering from 15,000 to $100,500 \mathrm{~km}^{2}$. In 346 non-permafrost areas, surface water can easily infiltrate into 347 groundwater at a rate of 10 to $70 \mathrm{~cm} / \mathrm{yr}$. Ye et al. [2004] find 348 that the ratio of maximum to minimum monthly discharge has 349 decreased from 1937 through 2000 in the upper Lena river 350 basin, concurrent with the Lena subregion. They also find that 351 the recession coefficient, the ratio of monthly discharge in 352 April to monthly discharge in December, during cold seasons 353 increased over the same period. These results imply that more 354 surface water is infiltrating as groundwater and increasing base 355 flows; they also speculate that regional permafrost degradation 356 plays an important role in these changes. 357

[21] Subsurface water storage that remains within the 358 active layer and is accessible to vegetation will strongly 359 impact terrestrial water, energy and carbon cycle processes 360 under a warming climate by providing additional moisture 361 for ET (latent energy flux) and plant growth. These changes 362 are consistent with positive vegetation growth and ET trends 363 for the Lena basin as derived from the global satellite record 364 [Zhang et al., 2008]. However, the net effect of these changes 365 on regional soil carbon stocks will depend upon sub-grid 366 scale variability in surface soil moisture conditions, which 367 are strongly interactive with local terrain and permafrost. $\quad 368$

[22] Besides representing a significant change in terrestrial 369 hydrology, the overall positive trend in TWS is consistent 370 with increasing precipitation trends and intensification of the 371 Arctic freshwater cycle with climate warming [White et al, 372 2007; Rawlins et al., 2010].

\section{Conclusion}

[23] This study quantifies the increase in TWS in the Lena 375 river basin during a 7-year period using a rigorous analysis 376 of GRACE data. We find that TWS increases twice as rap- 377 idly as in the rest of the basin in an area of discontinuous 378 permafrost near the center of the basin. We attribute most of 379 this observed change in TWS to an increase in subsurface 380 water storage. The estimated TWS increase in the Lena 381 subregion implies an average increase in the groundwater 382 table of $56 \pm 9 \mathrm{~cm}$ or groundwater recharging through areas 383 not underlain by permafrost, while changes in active layer 384 
385 thickness likely have little impact. We also estimate the bias 386 in P-ET using GRACE data to close the water budget. After 387 correcting for this bias, the TWS change from GRACE is 388 largely explained by an increase in P-ET. Our approach to 389 evaluate the bias in P-ET can be applied to other river basins 390 and provide important feedback on the accuracy of reanal391 ysis products.

392 [24] Acknowledgments. This work was performed at the Univ. of 393 California Irvine and at the Jet Propulsion Laboratory, and was supported 394 by grants from NASA's Cryospheric Science Program, Solid Earth and 395 Natural Hazards Program, Terrestrial Hydrology Program.

396 [25] The Editor thanks Balazs Fekete and an anonymous reviewer for 397 assisting with the evaluation of this paper.

\section{References}

399 Brown, J., et al. (1997), Circum-Arctic map of permafrost and ground-ice 400 conditions, U.S. Geol. Surv. Circum Pac. Map Ser., CP-45.

401 Cheng, M., and B. D. Tapley (2004), Variations in the Earth's oblateness 402 during the past 28 years, J. Geophys. Res., 109, B09402, doi:10.1029/ 403 2004JB003028

404 Derksen, C., A. Walker, and B. Goodison (2003), A comparison of 18 win405 ter seasons of in situ and passive microwave-derived snow water equiva406 lent estimates in western Canada, Remote Sens. Environ., 88, 271-282.

407 Johnson, A. I. (1967), Specific yield-Compilation of specific yields for 408 various materials, U.S. Geol. Surv. Water Supply Pap., 1662-D, 74.

409 Jones, L. A., and J. S. Kimball (2010), Daily global land surface parameters 410 derived from AMSR-E, digital media, Natl. Snow and Ice Data Cent., 411 Boulder, Colo.

412 Lammers, R. B., A. I. Shiklomanov, C. J. Vörösmarty, B. M. Fekete, and 413 B. J. Peterson (2001), Assessment of contemporary Arctic river runoff based 414 on observational discharge records, J. Geophys. Res., 106, 3321-3334.

415 Landerer, F. W., J. O. Dickey, and A. Güntner (2010), Terrestrial water 416 budget of the Eurasian pan-Arctic from GRACE satellite measurements 417 during 2003-2009, J. Geophys. Res., 115, D23115, doi:10.1029/ 418 2010JD014584

419 Muskett, R., and V. Romanovsky (2009), Groundwater storage changes in 420 Arctic permafrost watersheds from GRACE and in situ measurements, 421 Environ. Res. Lett., 4, 045009.

422 Paulson, A., S. Zhong, and J. Wahr (2007), Inference of mantle viscosity 423 from GRACE and relative sea level data, Geophys. J. Int., 171, 497-508. 424 Rawlins, M. A., H. Ye, D. Yang, A. Shiklomanov, and K. C. McDonald 425 (2009), Divergence in seasonal hydrology across northern Eurasia: 426 Emerging trends and water cycle linkages, J. Geophys. Res., 114, 427 D18119, doi:10.1029/2009JD011747
Rawlins, M. A., et al. (2010), Analysis of the arctic system for freshwater 428 cycle intensification: Observations and expectations, J. Clim., 23, 429 5715-5737.

Rodell, M., et al. (2004), The global land data assimilation system, Bull. 431 Am. Meteorol. Soc., 85(3), 381-394. 432

Rodell, M., et al. (2005), Global biomass variation and its geodynamic 433 effects, 1982-1998, Earth Interact., 9, 1-19. 434

Sahoo, A. K., et al. (2011), Reconciling the global terrestrial water budget 435 using satellite remote sensing, Remote Sens. Environ., 115(8), 1850-1865. 436

Serreze, M. C., D. H. Bromwich, M. P. Clark, A. J. Etringer, T. Zhang, and 437 R. Lammers (2002), Large-scale hydro-climatology of the terrestrial 438 Arctic drainage system, J. Geophys. Res., 108(D2), 8160, doi:10.1029/ 439 2001JD000919.

Serreze, M. C., A. P. Barrett, A. G. Slater, R. A. Woodgate, K. Aagaard, 441 R. B. Lammers, M. Steele, R. Moritz, M. Meredith, and C. M. Lee 442 (2006), The large-scale freshwater cycle of the Arctic, J. Geophys. 443 Res., 111, C11010, doi:10.1029/2005JC003424.

Shiklomanov, A., et al. (2006), Cold region river discharge uncertainty- 445 estimates from large Russian rivers, J. Hydrol., 326, 231-256. 446

Simmons, A. J., S. Uppala, D. Dee, and S. Kobayashi (2007), ERA-interim: 447 New ECMWF reanalysis products from 1989 onwards, ECMWF Newst., 448 $110,1-52$.

Swenson, S., D. Chambers, and J. Wahr (2008), Estimating geocenter 450 variations from a combination of GRACE and ocean model output, 451 J. Geophys. Res., 113, B08410, doi:10.1029/2007JB005338. 452

Tapley, B. D., S. Bettadpur, M. Watkins, and C. Reigber (2004), The grav- 453 ity recovery and climate experiment: Mission overview and early results, 454 Geophys. Res. Lett., 31, L09607, doi:10.1029/2004GL019920. 455

Tiwari, V. M., J. Wahr, and S. Swenson (2009), Dwindling groundwater 456 resources in northern India, from satellite gravity observations, Geophys. 457 Res. Lett., 36, L18401, doi:10.1029/2009GL039401. 458

Troy, T. J., J. Sheffield, and E. F. Wood (2011), Estimation of the terrestrial 459 water budget over northern Eurasia through the use of multiple data 460 sources, J. Clim., 24, 3272-3293.

Wahr, J M Molenar, and F. Bryan (1998), Time variability of the Earth's 462 gravity field: Hydrological and oceanic effects and their possible detec- 463 tion using GRACE, J. Geophys. Res., 103, 30,205-30,229. 464

Wahr, J., S. Swenson, and I. Velicogna (2006), Accuracy of GRACE mass 465 estinates, Geophys. Res. Lett, 33, L06401, doi:10.1029/2005GL025305. 466 White, D., et al. (2007), The arctic freshwater system: Changes and impacts, 467 J. Geophys. Res., 112, G04S54, doi:10.1029/2006JG000353. 468

Ye, H., et al. (2004), The impact of climatic conditions on seasonal river 469 đischarges in Siberia, J. Hydrometeorol, 5, 286-295. 470

Zhang, K., J. S. Kimball, E. H. Hogg, M. Zhao, W. C. Oechel, J. J. Cassano, 471 and S. W. Running (2008), Satellite-based model detection of recent 472 climate-driven changes in northern high-latitude vegetation productivity, 473 J. Geophys. Res., 113, G03033, doi:10.1029/2007JG000621. 474

Zhang, T., et al. (2005), Spatial and temporal variability in active layer 475 thickness over the Russian Arctic drainage basin, J. Geophys. Res., 476 110, D16101, doi:10.1029/2004JD005642. 